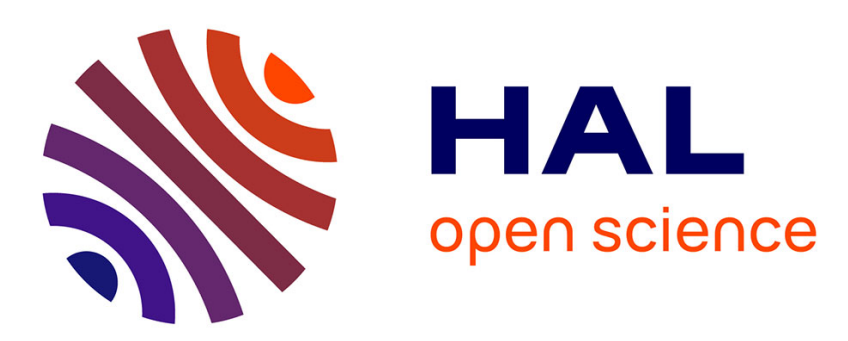

\title{
Underreporting of musculoskeletal disorders in 10 regions in France in 2009
}

Stéphanie Rivière, Emmanuelle Penven, Hélène Cadéac-Birman, Yves Roquelaure, Madeleine Valenty

\section{To cite this version:}

Stéphanie Rivière, Emmanuelle Penven, Hélène Cadéac-Birman, Yves Roquelaure, Madeleine Valenty. Underreporting of musculoskeletal disorders in 10 regions in France in 2009. American Journal of Industrial Medicine, 2014, 57, pp.1174-80. 10.1002/ajim.22364 . hal-03404328

\section{HAL Id: hal-03404328 \\ https://univ-angers.hal.science/hal-03404328}

Submitted on 26 Oct 2021

HAL is a multi-disciplinary open access archive for the deposit and dissemination of scientific research documents, whether they are published or not. The documents may come from teaching and research institutions in France or abroad, or from public or private research centers.
L'archive ouverte pluridisciplinaire HAL, est destinée au dépôt et à la diffusion de documents scientifiques de niveau recherche, publiés ou non, émanant des établissements d'enseignement et de recherche français ou étrangers, des laboratoires publics ou privés. 


\title{
Underreporting of Musculoskeletal Disorders in 10 Regions in France in 2009
}

\author{
Stéphanie Rivière, $\mathrm{Msc}^{1 *}{ }^{*}$ Emmanuelle Penven, $\mathrm{MD}^{2}{ }^{2}$ Hélène Cadéac-Birman, $\mathrm{MD},{ }^{3}$ \\ Yves Roquelaure, $\mathrm{PhD}^{4}{ }^{4}$ and Madeleine Valenty, ${ }^{\mathrm{MD}}{ }^{1}$
}

\begin{abstract}
Background Underreporting of occupational diseases (OD) has been quantified, in particular in the United States, but little information is available in other countries. The aim of this study was to evaluate underreporting of musculoskeletal disorders (MSD) in France in 2009.

Methods We calculated an indicator that approximated the underreporting rate of MSD in 10 regions of France. Two databases were used: data on OD compensated by insurance funding and data from the surveillance program for uncompensated work-related diseases. Analyses were performed for carpal tunnel syndrome (CTS) and elbow, shoulder, and lumbar spine MSD.

Results The underreporting rate was estimated at 59\% (range 52-64\%) for CTS, 73\% (range 67-79\%) for elbow MSD, 69\% (range 63-74\%) for shoulder MSD, and 63\% (range 50-76\%) for lumbar spine MSD.

Conclusions This study revealed that MSD are substantially underreported in France, as in the United States, despite the differences in workers' compensation systems. Am. J. Ind. Med. 57:1174-1180, 2014. (C) 2014 Wiley Periodicals, Inc.
\end{abstract}

KEY WORDS: occupational disease; surveillance; work-related musculoskeletal disorders; workers' compensation; MSD; epidemiology

\section{INTRODUCTION}

Work-related musculoskeletal disorders (MSD) are the main category of occupational diseases (OD) for workers in major industrial countries, and the social and economic impact of such disorders is substantial. In France in 2009, MSD represented $80 \%$ of all OD compensated by the national health insurance system (which covers about $70 \%$ of the French working population): about 41,000 cases of MSD

\footnotetext{
1Department of Occupational Health (DST), French Institute for Public Health Surveillance (InVS), Saint-Maurice, France

${ }^{2}$ University Hospital (CHU), Nancy, France

${ }^{3}$ Regional Directorates for Businesses, Competition Policy, Consumer Affairs, Labour and Employment (DIRECCTE), Work Medical Inspection, Toulouse, France

${ }^{4}$ LUNAM,University of Angers, Laboratory of Ergonomics and Epidemiology in 0ccupational Health, Angers, France

* Correspondence to: Stéphanie Rivière, Département Santé Travail, ARS, InVS, 10 chemin du Raisin, 31050 Toulouse Cedex,France.E-mail: stephanie.riviere @ars.sante.fr

Accepted 28 May 2014

D0I10.1002/ajim.22364. Published online in Wiley Online Library (wileyonlinelibrary.com)
}

received compensation at a total cost of $875,000,000 €$ [Cnam-TS, 2010]. Moreover, the number of cases of MSD receiving compensation had steadily increased since 1997 [Cnam-TS, 2010].

In France, the workers' compensation (WC) system for OD is based on a series of tables, themselves based on presumption of causality, which define the required criteria for compensation by social insurance funds. A disease is recognized as occupational if all the criteria in the corresponding table are met: that is, diagnostic criteria, time since the most recent exposure and conditions of exposure. The diseases detailed in these tables are all compensatable OD; about 100 are listed in the general national health insurance system and about 50 in the agricultural health insurance system [INRS, 2013]. An additional system of compensation was set up in 1993 in order to allow workers with diseases, which are not included in the list or those which do not meet the criteria appearing in the table to claim compensation under the same conditions as an OD.

However, as in other industrialized countries, the treatment of recognized OD offers only a partial view of 
the real situation of all work-related diseases (WRD) and is of limited value in providing information to form preventive policies because of underreporting, which may be substantial. To the best of our knowledge, the main studies attempting to quantify underreporting of OD have been carried out in the United States. Fan et al. showed in 2002 that only 52\% of workers with illness and injury reported filing WC claims [Fan et al., 2006]. According to studies carried out in various parts of the United States, underreporting of MSD ranged from $75 \%$ to $94 \%$ [Rosenman et al., 2000; Morse et al., 2001; Morse et al., 2005] and from $39 \%$ to $77 \%$ for carpal tunnel syndrome (CTS) [Biddle et al., 1998]. However, the extent of underreporting might be different in a country with a different workers' compensation system (for instance, France). Few publications have quantified underreporting of OD in France, in particular MSD. Data from the French surveillance program for upper-extremity musculoskeletal disorders showed at a national level that $47 \%$ of surgical CTS cases attributable to work did not receive compensation in 2003 [Ha et al., 2011]. Using data from the French surveillance program for uncompensated work-related disease (uc-WRD) for the year 2007 and OD workers' compensation data from the national health insurance system, we carried out a preliminary study in seven French regions in order to quantify underreporting [Rivière et al., 2012]. We showed that the underreporting rate of MSD ranged from $64 \%$ to $80 \%$. These findings are important in terms of cost, because in France failure to submit a work compensation claim involving medical treatment means that the cost of such treatment is shifted from the work compensation funding to the national health insurance system.

In order to update the estimation of underreporting on a larger population in 2009, we carried out a study to quantify underreporting of CTS and shoulder, elbow, and lumbar spine MSD in 10 areas by using data from the French surveillance program for uc-WRD and from OD workers' compensation systems (national health insurance system and agricultural workers' insurance system).

\section{MATERIALS AND METHODS}

\section{Study Population and Databases}

The study included 10 areas covered in 2009 by the ucWRD surveillance programme as well as by the national insurance system and the agricultural workers' insurance system (Aquitaine, Centre, Franche Comté, Limousin, MidiPyrénées, Nord-Pas de Calais, Pays de la Loire, Picardie, Poitou-Charentes, and Provence-Alpes-Côte d'Azur). It included salaried workers from the economic sectors covered by both insurance systems: agriculture/forestry/fishing, mining and manufacturing, wholesale and retail trade, construction, transportation and storage, service activities and financial, insurance, real estate, scientific and technical activities. Moreover, only salaried workers aged less than 60 years (minimum legal age of retirement in France in 2009) were included.

The uc-WRD surveillance program is based on a multiregional network of occupational physicians (OP) who volunteered to participate in the 2-week predefined observation period repeated every 6 months known as "uc-WRD Fortnights" (one in the first 6 months of the year, the other in the last 6 months of the year) [Valenty et al., 2012]. In France, all salaried workers undergo a mandatory, regularly scheduled health examination by a qualified OP. The participating OPs working in the regions covered by the surveillance system notified workers with uc-WRD from all the salaried workers seen during the "uc-WRD Fortnights."

Anonymized information recorded in each compensation system and in the uc-WRD surveillance program in 2009 comprised information on gender and age, geographical area, economic sector coded according to the National Institute of Statistics and Economic Studies (INSEE) nomenclature 2008 [INSEE, 2008] and, for the cases of uc-WRD or compensated OD, specific diagnoses and disease code (according to the International Classification of Diseases, 10th revision (ICD10)). In WC systems, cases were identified with information on the diagnosis, exposure and time since the most recent exposure corresponding to the definition of the OD tables. In the uc-WRD surveillance program, cases were identified with information on the diagnosis corresponding to the definition of tables of OD and if the OP considered that occupational exposure existed. For each case of uc-WRD, the OP notified whether the disease was reported but compensation rejected, reported but compensation under consideration, or not reported. No approval from an Ethics Committee or Institutional Review Board was necessary, since no biological samples were collected (only medical and administrative data were collected), and written informed consent was therefore not necessary. Indeed, in France, Human Subjects Committee review is only needed for clinical trials and biomedical research, not for use of anonymous medical data in epidemiological studies. For the uc-WRD surveillance program, an authorization for data computerization was provided by the CNIL (Commission nationale de l'informatique et des libertés). For the compensation data, an agreement exists between these insurance systems and the National Institute of Public Health, which allowed access to anonymized medical and administrative data and permitted their analysis from aggregate tables.

\section{Definition of MSD Cases}

We studied four specific MSD types for which the diagnoses corresponded to the criteria of the tables of 
compensatable MSD (traumatic cases of sudden onset were not considered as OD either in the WC system or in the ucWRD surveillance program).

- Shoulder MSD: shoulder tendinitis (M752), rotator cuff syndrome (M751), and frozen shoulder (M750).
We constructed an indicator of the rate of underreporting for a time period ( $t$ ) using the reporting stages of WRD presented in Figure 1. The underreporting rate taken into consideration in this study was for 1 year.

The indicator was defined as follows:

Number of unreported $\mathrm{MSD}^{(1 \text { in figure } 1)}$

Number of compensated $\mathrm{MSD}^{(4 \text { in figure } 1)}+\left(\right.$ Number of compensation rejected $\left.\mathrm{MSD}^{(2 \text { in figure } 1)}\right)$ or MSD being considered for compensation ${ }^{(3 \text { in figure } 1)}+$ number of unreported $\mathrm{MSD}^{(1 \text { in figure } 1)}$

- Lumbar spine MSD: radiculalgia due to herniated disc (M511) caused by vibration or handling of materials.

- Elbow MSD: ulnar tunnel syndrome (G562; G5622 in WRD program), hygroma (M703), epitrochleitis (M770), epicondylitis (M771) (or elbow tendinitis, M7782 in WRD program).

- CTS: G560 (representing 80\% of hand-wrist-finger MSD).

\section{Definition of Indicator of Underreporting Rate}

The underreporting rate (\%) can be defined as the ratio between the number of non-reported cases of a disease and the total number of cases of the disease (reported and not reported).
The indicator " $\mathrm{T}$ " of the underreporting rate was calculated for the year 2009 as follows:

- The numbers of unreported MSD, compensation for MSD rejected, and MSD being considered for compensation (Fig. 1) were extrapolated to the whole population by using the prevalence rates of MSD obtained in the uc-WRD surveillance program. The prevalence rates of uc-WRD and their $95 \%$ confidence interval (CI) were calculated by dividing the number of workers with MSD by the number of workers seen during the "uc-WRD Fortnight."

- The number of compensated MSD (Fig. 1) was obtained from the national health insurance and the agricultural workers' insurance systems for the year 2009.

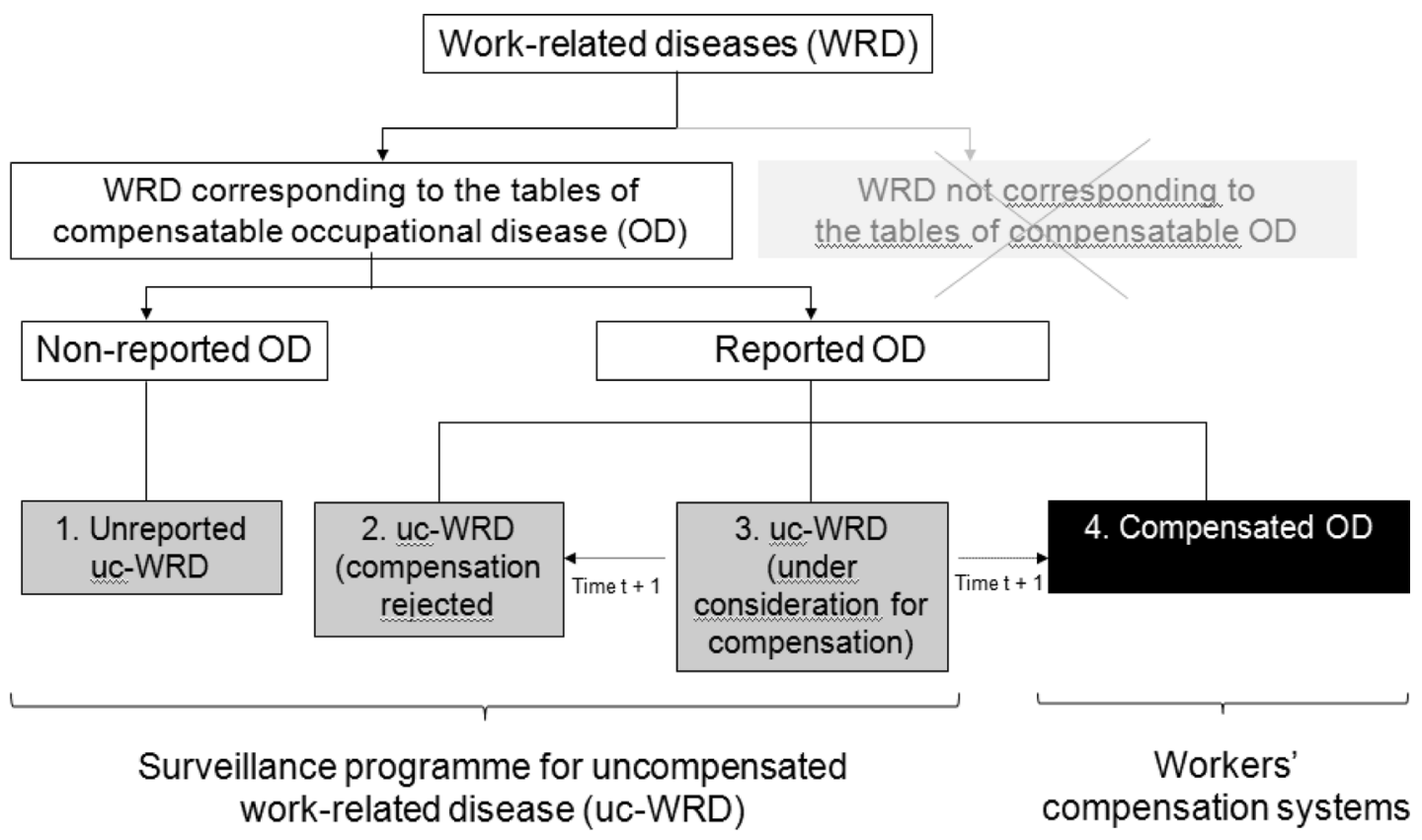

FIGURE 1. Reporting stages for work-related diseases (WRD) in the workers' compensation system and links with uncompensated work-related disease (uc-WRD) surveillance program. 
The indicator for the underreporting rate " $\mathrm{T}$ " was:

$$
\frac{\mathrm{P} \times \mathrm{a} \times \mathrm{N}}{\mathrm{OD}+(\mathrm{P} \times \mathrm{a} \times \mathrm{N})+\left(\mathrm{P}^{\prime} \times \mathrm{a} \times \mathrm{N}\right)} \times 100
$$

where "P" is the prevalence rate of unreported WRD, " $\mathrm{P}$ " the prevalence rate of reported but compensation rejected WRD and WRD being considered for compensation, "a" the mean number of WRD per worker, "N," the number of salaried workers in the 10 areas (INSEE National Employment Survey) and OD the number of compensated OD.

As it was not possible to construct a confidence interval for " $T$ " because it included several random variables, a range was calculated by using the limits of CI of prevalence rates for MSD in uc-WRD. The lower limit for " $T$ " corresponded to a minimized scenario using the lower limit of the CI for "P" and the upper limit of the CI for " $\mathrm{P}$ '." The upper limit for "T" corresponded to a maximized scenario using the upper limit of the CI for "P" and the lower limit of the CI for " $\mathrm{P}$.".

We calculated "T" only if the number of uc-WRC used to obtain the prevalence rates "P" and " $\mathrm{P}$ " " was equal to or greater than 5 .
The prevalence rates for uc-WRD and incidence rates for compensated MSD were presented per 100 person-years, hypothesizing that all the salaried workers were full-time workers during the entire year as no such data was available in the uc-WRD surveillance program. Analyses were performed using Microsoft Excel for Windows (Office 2007 version) for OD incidence rates and underreporting rate. Stata v. 11.0 was used for analysis of prevalence rates for uc-WRD and their $95 \% \mathrm{CI}$.

\section{RESULTS}

\section{Population}

The 10 areas included covered $40 \%$ of French salaried workers [INSEE, 2013]. In these areas, there were 6,155,943 salaried workers in the sectors selected for the study, representing $26 \%$ of French salaried workers [INSEE, 2013].

The incidence rate for all four specific compensated MSD types was 0.3 cases per 100 person-years and the prevalence rate for all four specific uc-MSD types was 1.4 cases per 100 person-years. Table I summarizes the incidence

TABLE I. Number and Prevalence of Notified uc-WRD (P and $P^{\prime}$ ) and Number and Incidence of Compensated OD (OD) for the Four Specific Types of MSD, According to Gender (Rates Per 100 Person-Years)

CTS

\begin{tabular}{|c|c|c|c|c|c|}
\hline \multicolumn{6}{|l|}{ Total } \\
\hline \multirow[t]{2}{*}{ Unreported uc-WRD (P) } & $\mathrm{n}$ & 203 & 244 & 286 & 41 \\
\hline & Prevalence $(\mathrm{Cl})$ & $0.31(0.27-0.36)$ & $0.38(0.33-0.42)$ & $0.44(0.39-0.49)$ & $0.06(0.04-0.08)$ \\
\hline \multirow{2}{*}{$\begin{array}{l}\text { Rejected or under consideration } \\
\text { uc-WRD }\left(\mathrm{P}^{\prime}\right)\end{array}$} & $\mathrm{n}$ & 66 & 49 & 74 & 8 \\
\hline & Prevalence (Cl) & $0.10(0.08-0.13)$ & $0.08(0.05-0.1)$ & $0.11(0.09-0.14)$ & $0.01(0.003-0.02)$ \\
\hline \multirow[t]{2}{*}{ OD } & $\mathrm{n}$ & 7,377 & 3,792 & 5,355 & 1,391 \\
\hline & Incidence & 0.12 & 0.06 & 0.09 & 0.02 \\
\hline \multicolumn{6}{|l|}{ Women } \\
\hline \multirow[t]{2}{*}{ Unreported uc-WRD (P) } & $\mathrm{n}$ & 118 & 86 & 124 & 8 \\
\hline & Prevalence $(\mathrm{Cl})$ & $0.53(0.43-0.62)$ & $0.38(0.30-0.47)$ & $0.55(0.46-0.65)$ & $0.04(0.01-0.06)$ \\
\hline \multirow{2}{*}{$\begin{array}{l}\text { Rejected or under consideration } \\
\text { uc-WRD }\left(\mathrm{P}^{\prime}\right)\end{array}$} & $\mathrm{n}$ & 51 & 21 & 43 & 1 \\
\hline & Prevalence $(\mathrm{Cl})$ & $0.23(0.17-0.29)$ & $0.09(0.05-0.13)$ & $0.19(0.14-0.25)$ & nc \\
\hline \multirow[t]{2}{*}{ OD } & $\mathrm{n}$ & 4,508 & 1,836 & 2,820 & 245 \\
\hline & Incidence & 0.19 & 0.08 & 0.12 & 0.01 \\
\hline \multicolumn{6}{|l|}{ Men } \\
\hline \multirow[t]{2}{*}{ Unreported uc-WRD (P) } & $n$ & 85 & 158 & 162 & 33 \\
\hline & Prevalence $(\mathrm{Cl})$ & $0.20(0.16-0.24)$ & $0.37(0.31-0.43)$ & $0.38(0.32-0.44)$ & $0.08(0.05-0.10)$ \\
\hline \multirow{3}{*}{$\begin{array}{l}\text { Rejected or under consideration } \\
\text { uc-WRD }\left(\mathrm{P}^{\prime}\right)\end{array}$} & $\mathrm{n}$ & 15 & 28 & 31 & 7 \\
\hline & & & & & \\
\hline & Prevalence $(\mathrm{Cl})$ & $0.04(0.02-0.06)$ & $0.07(0.05-0.09)$ & $0.07(0.05-0.10)$ & $0.02(0.004-0.03)$ \\
\hline \multirow[t]{2}{*}{ OD } & $\mathrm{n}$ & 2,869 & 1,956 & 2,535 & 1,146 \\
\hline & Incidence & 0.08 & 0.05 & 0.07 & 0.03 \\
\hline
\end{tabular}

nc: not calculated ( $<5$ cases). 
rate for each specific compensated MSD type, and the prevalence rate for each specific MSD type notified in the ucWRD surveillance system for the 64,929 workers included by the 914 participating occupational physicians (participation rate $26.3 \%$ ). The mean number of uc-WRD per worker (denoted "a") was 1.0 for each specific MSD type.

\section{Representativeness of the Sample Included in the uc-WRD Surveillance System}

Comparison of socioeconomic status of the workers we surveyed in the 10 areas and sectors studied and the salaried workers estimated in the 2009 French census showed no major differences. Men were slightly overrepresented in our sample (65.5\% vs. $60.8 \%)$. Most economic sectors were appropriately represented (agriculture/forestry/fishing 1.9\% vs. $2.4 \%$; construction $10.8 \%$ vs. $10.2 \%$; wholesale and retail trade $19.0 \%$ vs. $19.8 \%$; transportation and storage $7.0 \%$ vs. $8.2 \%)$. However, mining and manufacturing were slightly overrepresented in the sample $(31.0 \%$ vs. $23.9 \%)$ whereas service activities and financial, insurance, real estate, scientific and technical activities were slightly underrepresented $(30.4 \%$ vs. $35.6 \%)(P<0.05)$.

\section{Underreporting Rates}

Underreporting rates varied from $62 \%$ to $75 \%$ (Table II). The underreporting rate was lower for CTS than for shoulder and elbow MSD for both genders. Few variations were observed according to gender.

Few differences in underreporting rate according to age were observed for CTS, or elbow or lumbar spine MSD (Table III). Despite the wide range, the underreporting rate for shoulder MSD appeared to decrease with age (75\% to $61 \%$ ). Few differences in underreporting rate were observed according to economic sector (Table III).

\section{DISCUSSION}

Our study is one of the first to undertake large-scale evaluation of the extent of underreporting of four specific

TABLE II. Underreporting Rate (\%) for the Four Specific Types of MSD According to Gender

Total \% (range) Women \% (range) Men \% (range)

\begin{tabular}{lccc}
\hline CTS & $59(52-64)$ & $56(47-64)$ & $64(55-72)$ \\
Elbow MSD & $73(67-79)$ & $70(59-79)$ & $75(69-82)$ \\
Shoulder MSD & $69(63-74)$ & $64(56-72)$ & $74(66-79)$ \\
Lumbar spine & $63(50-76)$ & nc & $62(46-75)$ \\
\hline
\end{tabular}

nc, not calculated for lumbar spine for women ( $<5$ cases).
TABLE III. Underreporting Rate (\%) for the Four Specific Types of MSD According to Age and Economic Sectors

\begin{tabular}{lccc} 
& $\begin{array}{c}\text { CTS \% } \\
\text { (range) }\end{array}$ & $\begin{array}{c}\text { Elbow } \\
\text { MSD \% } \\
\text { (range) }\end{array}$ & $\begin{array}{c}\text { Shoulder } \\
\text { MSD \% } \\
\text { (range) }\end{array}$ \\
\hline Age group & & & \\
25-34 years & $64(44-79)$ & $\mathrm{nc}$ & $75(53-90)$ \\
35-44 years & $55(42-66)$ & $75(66-84)$ & $73(62-82)$ \\
45-54 years & $61(52-69)$ & $71(63-79)$ & $67(59-74)$ \\
55-59 years & $52(36-67)$ & $72(50-84)$ & $61(46-71)$ \\
Economic sector & & & \\
Mining and manufacturing & $54(44-63)$ & $68(59-77)$ & $68(60-75)$ \\
Construction & $72(59-78)$ & $\mathrm{nc}$ & $71(54-84)$ \\
Wholesale and retail trade & $60(44-73)$ & $73(57-85)$ & $70(55-81)$ \\
Transportation and storage & $65(31-76)$ & $\mathrm{nc}$ & $\mathrm{nc}$ \\
Service activities and financial, & $70(56-79)$ & $\mathrm{nc}$ & $73(60-84)$ \\
$\quad$ insurance, real estate, & & & \\
$\quad$ scientific and technical & & & \\
$\quad$ activities & & & \\
\hline
\end{tabular}

The $<25$ years age group, the agricultural sector and lumbar spine MSD are not presented ( $<5$ cases).

nc, not calculated for elbow MSD for 25-34 years age group, or for construction, transportation and service sectors or for shoulder MSD for transportation $(<5$ cases).

types of MSD in France. In the 10 geographical areas studied, between $59 \%$ and $73 \%$ of work-related MSD were not reported to the workers' compensation systems in 2009, although, they could have been.

Despite the differences in study design and survey population, our results are consistent with those obtained in other studies carried out in the United States showing that 75$94 \%$ of MSD were not reported [Rosenman et al., 2000; Morse et al., 2001; Morse et al., 2005]. However, more precise comparisons seem difficult, since the classification and coding systems of OD sometimes differed between countries. In our study, few variations in underreporting rate were observed according to gender, by contrast with the study of Biddle et al., which showed that women were more likely than men to report occupational disease [Biddle et al., 1998]. Few variations were found according to economic sector, showing that underreporting is a widespread phenomenon, in agreement with Morse's study on MSD underreporting in Connecticut State [Morse et al., 2005]. We found no clear variations in underreporting rate according to age, in agreement with Biddle et al. for occupational diseases as a whole [Biddle et al., 1998]. We found, however, that the underreporting rate for CTS was lower than for shoulder and elbow MSD. To the best of our knowledge, no other study has compared the underreporting rates for different MSD types. However, in North American studies, underreporting varied between $75 \%$ and $94 \%$ for all MSD and between only $39 \%$ and $77 \%$ for CTS alone [Biddle 
et al., 1998; Rosenman et al., 2000; Morse et al., 2001; Morse et al., 2005]. More effective and more easily accessible treatment for CTS (in particular surgery) may explain this better reporting rate: indeed, when surgery is performed promptly, the consequences for worker recovery and return to work have been reported to be less serious [Foley et al., 2007]. The estimated underreporting rate for CTS in our study was consistent with but higher than the results of the French surveillance system for upper-extremity musculoskeletal disorders, which showed that at a national level $47 \%$ of surgical CTS cases attributable to work, did not receive compensation in 2003 [Ha et al., 2011]. However, this first evaluation, based on attributable fractions, was not precise, and the proportion of cases of non-compensated CTS was calculated only on surgical cases.

A similar study of three specific MSD types in only seven geographical areas in 2007 showed that the underreporting rate was $74 \%$ for shoulder MSD, $64 \%$ for CTS and $80 \%$ for lumbar spine MSD [Rivière et al., 2012]. The 2009 results for each specific MSD type, in particular for the lumbar spine, were systematically lower than those calculated in 2007, although, the difference was not great. When the findings for 2009 and for 2007 based on the same six areas and the same economic sectors were compared, the decrease in the underreporting rates by several points was still found (results not shown). This decrease was based on only 2 years and on a limited section of the population, but it may reflect a real improvement in OD reporting. Indeed, the incidence rates of MSD receiving compensation as OD increased, whereas the prevalence rates of MSD in the WRD surveillance program remained relatively steady or decreased. The increase in MSD receiving compensation as OD might be a simple consequence of the overall increase in work-related MSD, but the concomitant stability of the prevalence of uc-WRD suggests that this change might reflect an improvement in reporting. This improvement might partly be linked to greater awareness of work-related MSD by workers. A national media campaign on MSD (TV, press, and radio) was launched in France in 2008 in order to improve awareness of work-related MSD in the general population. The results, evaluated by a study of the Ministry of Labour, showed that $61 \%$ of salaried workers heard of MSD for the first time during this media campaign (only $22 \%$ were aware of them before) [Etienne et al., 2011]. This trend needs to be confirmed over a longer period of follow-up.

Our indicator has certain limitations. Firstly, it is not a statistical estimate. The range was calculated with the CI of prevalence rates in the uc-WRD surveillance program. We hypothesized that data collection over two 2-week periods by participating occupational physicians working in different economic sectors would allow estimation of annual prevalence rates and numbers of cases of WRD. The prevalence rate was relatively stable from one "uc-WRD Fortnight" to another in all 10 areas (e.g., $0.11 \%$ vs. $0.09 \%$ for lumbar spine MSD), suggesting that this is probably close to the yearly rate.
The representativeness of the workers followed in the WRD surveillance program showed slight differences from the national census: women were underrepresented and the mining and manufacturing sector was slightly overrepresented. These differences partly reflect the organization of occupational medicine in France (intervals between health examinations differ according to occupational risks).

Moreover, the number of reported WRD was assessed by adding compensated OD, reported but compensation rejected WRD, and WRD under consideration for compensation. Some of the cases of uc-WRD under consideration for compensation at the beginning of the year 2009 received compensation during the year, and could already have been taken into account in the number of compensated OD. It was not possible to know if the uc-WRD that were under consideration for compensation were in fact recognized during the year. However, this issue would have had a limited impact because MSD under consideration for compensation accounted for only around $10 \%$ of the denominator.

In the uc-WRD surveillance program, the inclusion of MSD that corresponded to the tables of OD was based only on the diagnosis, whereas other factors (interval since the most recent exposure and conditions of exposure) are also used to define compensatable OD. However, complementary analyses taking into account exposure notified by the OP showed a variation of only 1-2 points in the underreporting rate (results not shown).

Finally, although, there were uncertainties as to the number of MSD estimated from the WRD surveillance program, their impact on the estimated underreporting rate can be considered limited. For instance, a $10 \%$ variation in the yearly number of unreported WRD would lead to a variation of $1-2 \%$ in the underreporting rate. We therefore believe our indicator provides a good representation of the degree of underreporting.

Despite these limitations, our results are important for quantifying underreporting of MSD in France. They can be used by the National Commission to evaluate of the cost of treatment of OD borne by the national health insurance system instead of by workers' compensation funding [Diricq, 2011]. Moreover, although workers' compensation systems are very different from one country to another (e.g., the United States and France), this study revealed that MSD are substantially underreported regardless of the WC system. However, the reasons for underreporting might be different because of differences in the health systems. In France, the national health insurance system permits everybody to receive care in public or private hospitals, whether they benefit from workers' compensation system or not.

This study will continue in the coming years in order to confirm the changes observed over a longer period of time and to assess the impact of recent legislative changes on underreporting rates, in particular regarding the criteria used to define MSD as OD. 


\section{ACKNOWLEDGMENTS}

The authors thank the workers' compensation systems that participated in this study (Régime Général de la Sécurité Sociale and the Mutualite Sociale Agricole) and the occupational physicians who took part in the uc-WRD surveillance program. No external funds were used to conduct this study.

\section{REFERENCES}

Biddle J, Roberts K, Rosenman KD, Welch EM. 1998. What percentage of workers with work-related illnesses receive workers' compensation benefits? J Occup Environ Med 40(4):325-331.

Cnam-TS. 2010. [Internet]. Paris (France). TMS: Développer des plans de prévention durables pour réduire la progression du risque. [Accessed Sept.9, 2013] Available from: http://www.risquesprofessionnels.ameli. fr/fileadmin/user_upload/document_PDF_a_telecharger/fiches_completes_PNAC/Fiche\%20TMS.pdf.

Diricq N. 2011. Rapport de la commission instituée par l'article L, 176-2 du code de la sécurité sociale. Paris. 193 p. [Accessed Sept.9, 2013] Available from : www.securite-sociale.fr/IMG/pdf/11_diricq.pdf.

Etienne P, Groléas L, Lebret A. 2011. Quel bilan tirer de la campagne de communication TMS 2008-2010? Proceedings of the 3ème Congrès francophone sur les troubles musculosquelettiques. Échanges et pratiques sur la prévention 2011 May 26-27 Grenoble, France. HALSHS [Internet]; 8 p. [Accessed Sept.9, 2013] Available from: http:// halshs.archives-ouvertes.fr/halshs-00602213.

Fan JZ, Bonauto DK, Foley MP, Silverstein BA. 2006. Underreporting of work-related injury or illness to workers' compensation: Individual and industry factors. J Occup Environ Med 48:914-922.

Foley M, Silverstein B, Polissar N. 2007. The economic burden of carpan tunnel syndrome: Long-term earnings of CTS claimants in Washington State. Am J Ind Med 50(3):155-172.

Ha C, Brière J, Plaine J, Fouquet N, Roquelaure Y, Imbernon E. 2011 Occupational health indicators from the French epidemiological surveillance programme of work-related musculoskeletal disorders. Proceedings of the 22nd International Conference on Epidemiology in
Occupational Health EPICOH 2011 Sept. 7-9, Oxford, UK. Occup Environ Med 68(Suppl 1):A31. doi: 10.1136/oemed-2011-100382.99

INRS. 2013. [Internet] Paris (France). Tableaux des maladies professionnelles - Guide d'accès et commentaires. [Accessed Sept.9, 2013] Available from: http://www.inrs-mp.fr/mp/cgi-bin/mppage.pl? French.

Institut National de la Statistique et des Etudes Economiques (INSEE) 2008. [Internet] Paris (France). Nomenclature d'activités françaiseNAF rév. 2, 2008. [Accessed Sept. 9, 2013] Available from: http://www. insee.fr/fr/methodes/default.asp?page $=$ nomenclatures $/$ naf2008/naf2008. htm.

Institut National de la Statistique et des Etudes Economiques (INSEE). 2013. [Internet] Résultats du recensement de la population-2009. [Accessed Sept. 9 2013] Available from: http://www.recensement-2009. insee.fr/home.action.

Morse T, Dillon C, Warren N, Hall C, Hovey D. 2001. Capturerecapture estimation of unreported work related musculoskeletal disorders in Connecticut. Am J Ind Med 39:636-642.

Morse T, Dillon C, Kenta-Bibi E, Weber J, Diva U, Warren N, Grey M. 2005. Trends in work-related musculoskeletal disorder reports by year, type and industrial sector: A capture-recapture analysis. Am J Ind Med 48:40-49.

Rivière S, Chevalier A, Penven E, Cadéac-Birman H, Roquelaure Y, Valenty M. 2012. Estimation of underreporting of musculoskeletal diseases (MSDs) in seven French regions in 2007. Bull Epidémiol Hebd 22-23:268-271. French. Available from: http://www.invs.sante.fr/fr./ Publications-et-outils/BEH-Bulletin-epidemiologique-hebdomadaire.

Rosenman KD, Gardiner JC, Wang J, Biddle J, Hogan A, Reilly MJ, Roberts K, Welch E. 2000. Why most workers with occupational repetitive trauma do not file for workers' compensation. J Occup Environ Med 42(1):25-33.

Valenty M, Homère J, Mevel M, Dourlat T, Garras L, Brom M, Imbernon E. 2012. Surveillance programme of work-related diseases (WRD) in France. Saf Health Work 3:67-70.

This study was performed at the French Institute for Public Health Surveillance (InVS). Disclosure Statement: The authors report no conflicts of interests. 